\title{
EDUCAÇÃO AMBIENTAL APLICADA À GESTÃO DE RESÍDUOS SÓLIDOS: A INICIATIVA INOVADORA DO PROGRAMA CONDOMÍNIO SUSTENTÁVEL
}

\author{
Luís Gustavo Bet ${ }^{1}$ \\ Renato Prado ${ }^{2}$ \\ Mara Prado ${ }^{3}$ \\ Helena Pilotto Benaque ${ }^{4}$
}

Resumo: O Programa Condomínio Sustentável é uma iniciativa inovadora que utiliza a Educação Ambiental para promover a conscientização sobre a importância da utilização dos recursos de forma mais sustentável. A consultoria produz informações para sensibilizar os gestores, moradores e funcionários dos condomínios, no âmbito dos resíduos sólidos, uso racional da água e eficiência energética. O programa dissemina inúmeros aspectos da sustentabilidade, mas tem ênfase na gestão dos resíduos, uma temática fundamental para a sociedade moderna e que tem forte impacto na emergência climática e, por conseguinte, no atual cenário de pandemia e pós pandemia, demonstrando a necessidade premente da mudança de hábitos para evitar cenários futuros mais dramáticos ainda.

Palavras-chave: Educação Ambiental; Sustentabilidade; Gestão de Resíduos Sólidos; Consultoria Ambiental; Inovação.

Abstract: An innovative initiative that uses environmental education to promote awareness through the importance of using resources in a more sustainable way. The consultancy produces information to raise awareness among managers, residents and employees of condominiums, in the scope of solid waste, rational use of water and energy efficiency. The program disseminates numerous aspects of sustainability, but has an emphasis on waste management, a fundamental issue for modern society, which has a strong impact on the climate emergency and therefore in the current pandemic and post-pandemic scenario, demonstrating the pressing need for change habits to avoid even more dramatic future scenarios.

Keywords: Environmental Education; Sustainability; Waste Management; Environmental Consulting; Innovation.

1 Universidade Federal de São Paulo. E-mail: luisgustavo.bet@gmail.com.

2 Programa Condomínio Sustentável. E-mail: renato.prado.br@gmail.com.

3 Programa Condomínio Sustentável. E-mail: maraprado@uol.com.br.

4 Programa Condomínio Sustentável. E-mail: hbenaque@gmail.com. 


\section{Introdução}

Confrontados por uma pandemia que impactou profundamente nossa sociedade globalizada, para além da área da saúde, fomos forçados a mudar radicalmente nossos hábitos e com isso a repensar inúmeros aspectos de nossas vidas. Em um recente texto, o filósofo francês Bruno Latour (NOUAILLAS, 2020), nos trouxe uma reflexão sobre a necessidade de mudanças nas formas como vivemos e exploramos o planeta.

Segundo Bruno Latour,

a crise da saúde está inserida em algo que não é uma crise - apenas passageira - mas uma mudança ecológica duradoura e irreversível.

Assim, constatamos que em sua temporalidade, a pandemia como crise sanitária será provavelmente superada nalgum dia, já a crise climática, ou mais precisamente a emergência climática, esta não será passageira e produzirá transformações e consequências às quais teremos que nos adaptar. Neste momento de profunda crise civilizatória, há que se fazer duas perguntas fundamentais: qual o futuro que queremos? E como chegaremos até lá?

Diante deste cenário, é imprescindível repensar as ações humanas tanto individuais como coletivas. As temáticas socioambientais são urgentes e devem receber a atenção de todas as nações em prol da perenização da raça humana e das demais espécies do planeta. Uma dessas temáticas é a gestão dos resíduos sólidos, que deve ser prioritariamente considerada. Para tanto, é necessário que a população assuma sua parcela, no âmbito da responsabilidade compartilhada, e que pressione o poder público para implementar as medidas necessárias para a otimização da gestão dos resíduos e mais amplamente também da cadeia de produção, consumo e descarte dos mesmos.

A gestão dos resíduos sólidos é uma atividade fundamental e complexa que está diretamente relacionada à qualidade de vida nas cidades. Apesar disso, a sociedade não dedica a devida atenção que o assunto exige, pois ainda associa o conceito de resíduo à ideia de "lixo". Lixo é uma forma ultrapassada de se referir ao resíduo, que conceitualmente é definido como todo produto ou objeto rejeitado pelo homem, sem valor e uso pertinente (VELLOSO, 2008, p. 1954). Em suma, resíduo é o produto que, após utilizado, não tem mais valor econômico ou social.

Durante o processo de urbanização, o saneamento básico, no qual a questão dos resíduos sólidos está inserida, tornou-se um problema crônico para as cidades e um imenso desafio aos gestores municipais (JACOBI; BENSEN, 2011, p. 135). Pragas e epidemias registradas ao longo da história também se impuseram como prioridade nas questões sanitárias dos processos de organização do ambiente urbano, dando dimensões ainda mais expressivas aos desafios impostos à gestão pública. Não bastasse a discrepância social 
evidente e brutal, os municípios brasileiros enfrentam um outro tipo de desigualdade: a ambiental. $\mathrm{E}$ isto impacta diretamente as populações mais vulneráveis em virtude da precarização dos serviços de saneamento e da gestão dos resíduos sólidos urbanos, caracterizada pela falta de coleta, disposição inadequada dos resíduos, queima ao ar livre de resíduos e dejetos, representando assim uma fonte de poluentes atmosféricos nocivos à saúde humana (ALVES, 2007, p. 302).

A destinação dos resíduos gerados por mais de sete bilhões de pessoas no planeta representa um desafio ambiental premente por se tratar de um fator agravante da emergência climática global. Para além da destinação adequada dos resíduos sólidos, é imperativo promover na sociedade uma ampla ação de Educação Ambiental, que contemple ainda os conceitos de consumo consciente, não geração, redução, reutilização de produtos, segregação e destinação adequada como formas de contribuir para a minimização do volume gerado, mitigando assim os impactos ambientais deste processo (BRAGA JUNIOR; PINHEIRO, 2013, p.66; SOUSA et al., 2016, p.4).

Nas cidades modernas, metrópoles e megalópoles, a densidade populacional cresce continuamente e a tendência à verticalização se impõe como alternativa, face à carência de espaço e à demanda por moradia. Nesse contexto, as edificações têm aumentado suas proporções buscando abrigar sempre mais pessoas, famílias e negócios. Assim, condomínios têm se transformado em verdadeiras minicidades, podendo chegar a milhares de residentes que, por conseguinte, geram toneladas de resíduos diariamente, fazendo com que sua gestão e manejo se tornem questões complexas para serem administradas.

Com vistas a essa demanda e considerando seu potencial, o Programa Condomínio Sustentável (PCS) ajustou seu foco para os condomínios residenciais verticais, tendo definido como escopo os prédios acima de cinco andares e com elevador. Partindo destes parâmetros, o programa elenca a gestão de resíduos, a eficiência energética e o uso racional da água como eixos estruturantes e insere a Educação Ambiental como elemento transversal a todos eles, tendo em vista sua relevância na disseminação dos conceitos e ampliação das práticas sustentáveis. Entendendo, por extensão, a importância dos conceitos da sustentabilidade como pano de fundo, o programa buscou como base de inspiração os "Objetivos Globais" instituídos pelo PNUD (Programa das Nações Unidas para o Desenvolvimento), que incluem os 17 ODS (Objetivos de Desenvolvimento Sustentável), esses mesmos uma evolução dos antigos ODM (Objetivos do Milênio) que foram estabelecidos no início do século (ONU, 2015). Os ODS incluem temas como a mudança global do clima, inovação, consumo e produção responsáveis, cidades e comunidades sustentáveis, entre outras prioridades. No recorte específico dos resíduos, destacam-se 5 ODS relacionados com a temática: 6 - Água Potável e Saneamento, 11 - Cidades e Comunidades Sustentáveis, 12 - Consumo e Produção Responsáveis, 13 - Ação Contra a Mudança Global do Clima, 14 Vida na Água e 15 - Vida terrestre.

Revbea, São Paulo, V. 15, № 5: 282-298, 2020. 
Partindo dessas primícias, o PCS, vem contribuindo para 0 aprimoramento da gestão de resíduos sólidos domiciliares (RSD) e do consumo energético por meio da Educação Ambiental. Trata-se de uma iniciativa inovadora, com forte potencial de replicação de suas ações e de seus benefícios para outros municípios, regiões e países.

O presente artigo visa compartilhar as experiências e os desafios enfrentados na implementação deste programa com o objetivo de demonstrar as vantagens da aplicação de ações de Educação Ambiental em condomínios como instrumento capaz de promover mudanças comportamentais necessárias que poderão impactar a qualidade de vida das presentes e futuras gerações.

\section{Educação Ambiental aplicada à gestão de resíduos sólidos}

Diante dos desafios contemporâneos, a Educação Ambiental é um eficiente aliado no combate aos problemas socioambientais do planeta. Vale destacar, nesse sentido, o conceito desenvolvido no livro Salto para o Futuro, onde o autor José Silva Quintas relaciona o papel integrador da Educação Ambiental no processo da gestão ambiental.

Segundo Quintas (2008, p.3), a Educação Ambiental tem como objetivo

...proporcionar condições para o desenvolvimento de capacidades, (nas esferas dos conhecimentos, das habilidades e das atitudes) visando a intervenção individual e coletiva, de modo qualificado, tanto na gestão do uso dos recursos ambientais quanto na concepção e aplicação de decisões que afetam a qualidade do meio ambiente, seja ele físico-natural ou construído.

Por extensão, o conceito de Educação Ambiental abrange também o fortalecimento da cidadania e a conscientização sobre as inter-relações indivíduo e meio ambiente, principalmente na sua capacitação como agente transformador e crítico, ativamente envolvido na construção de ações e políticas públicas que sejam ambientalmente, socialmente e economicamente justas (FREIRE, 1980, p. 26).

Essa conexão está contemplada na Lei Federal no 12.305/10 que instituiu a Política Nacional de Resíduos Sólidos (PNRS) (BRASIL, 2010), proporcionando a instrumentalização para ampliação das práticas mais adequadas na gestão de resíduos em toda suas etapas, incluindo a adoção de instrumentos colaborativos e do uso da Educação Ambiental como diretriz dos processos, conforme consta do capítulo 1.12 específico para essa temática, que destaca dentre outros tópicos, a importância e valorização do conceito dos 3R's, em ordem de prioridade: reduzir reutilizar e reciclar os resíduos sólidos. A prevenção e a precaução na geração dos resíduos sólidos, a visão sistêmica 
e o desenvolvimento sustentável podem contribuir para minimizar o gasto de recursos e são alguns dos princípios basilares do PNRS. Para tanto, é preciso aprofundar a Educação Ambiental e criar mecanismos de estímulo à implantação das ações (SILVA, 2017, p. 10). O plano propõe as diferentes formas de atuação da Educação Ambiental, evidenciando quatro principais: tipo 1 - Informações orientadoras e objetivas para a população, tipo 2 Sensibilização/mobilização das comunidades diretamente envolvidas, tipo 3 Informação, sensibilização ou mobilização para o tema do resíduos sólidos desenvolvidos em ambiente escolar, e, por último, o tipo 4 - Campanhas e ações pontuais de mobilização.

A PNRS representou um expressivo avanço materializando as discussões e preocupações evocadas desde algumas décadas anteriores. Entretanto, como a maioria das leis no Brasil, falta uma estruturação e interação entre os poderes, resultando em dificuldades de execução local e intersetorial (MAIELLO; BRITTO; VALLE, 2018, p. 27). Mesmo assim, na PNRS, a gestão integrada foi um conceito reforçado e tratado como imprescindível, principalmente nas regiões metropolitanas e nas zonas costeiras no litoral de São Paulo.

No âmbito regional da Baixada Santista, vale destacar que o conceito da Educação Ambiental foi amplamente contemplado como uma da diretrizes das ações do Plano Regional de Gestão Integrada dos Resíduos Sólidos da Baixada Santista (PRGIRS-BS) e do Plano de Gestão Integrada do Município de Santos, para o qual o PCS contribui, desde 2017, como agente multiplicador de boas práticas para gestão de resíduos sólidos residenciais, buscando promover a segregação, o descarte correto e a destinação adequada, além da participação social.

O PRGIRS-BS disponibiliza uma base para a elaboração de práticas mais sustentáveis na região através das contribuições, sobretudo, relacionadas à Educação Ambiental. A diretriz de número 3, intitulada "Educação Ambiental, Mobilização Social, e Comunicação", tem dentre suas estratégias a elaboração dos planos municipais de Educação Ambiental. A construção desse plano envolveu diversas instituições e interessados da sociedade civil, resultando numa série de propostas, incluindo estratégias para a Educação Ambiental, tais como: elaboração de planos municipais de Educação Ambiental; formação e capacitação de pessoas; campanhas visando a redução e a reutilização dos resíduos sólidos; comunicação e divulgação; combate à disposição irregular de resíduos e valorização de boas práticas. O detalhamento e prazos de cada uma delas foi realizado de forma minuciosa com o intuito de facilitar a aplicação efetiva das ações pelo poder público, demonstrando métodos objetivos para esta implementação.

No âmbito municipal, na cidade de Santos, dentre as inovações implementadas pela Secretaria Municipal de Meio Ambiente (SEMAM), os programas de Educação Ambiental vêm obtendo resultados significativos. Dentre esses, cabe ressaltar além do PCS, o projeto Composta Santos, uma 
iniciativa aprovada no edital de 2017 do Fundo Nacional de Meio Ambiente, com financiamento do Fundo Socioambiental da Caixa. O projeto foi inspirado no Composta São Paulo e teve expressivo êxito no envolvimento de grande contingente populacional no processo educativo e de conscientização ambiental ao distribuir mais de 2000 composteiras/minhocários domésticos e orientações sobre práticas de compostagem em diferentes níveis. Ainda em 2017, foi implementada em Santos a lei municipal complementar de № 952/2017, que instituiu o Programa Socioambiental de Coleta Seletiva Solidária "Recicla Santos", com a caracterização das figuras do grande gerador comercial e residencial, implicando para ambos a obrigatoriedade da segregação dos resíduos em duas frações (secos recicláveis e úmidos orgânicos com rejeitos). A aplicação dessa nova lei municipal, juntamente com outras iniciativas envolvendo a Educação Ambiental, possibilitaram um significativo crescimento no volume da coleta seletiva no município, com o aumento do índice de reciclagem em $321 \%$ em apenas 3 anos, passando de pouco mais de $3 \%$ em 2016 para aproximadamente 18\% em 2019, um dos maiores do país, segundo dados da Prefeitura Municipal de Santos.

Neste contexto, considerando que o município é um dos mais verticalizados do país, cabe ressaltar que o PCS atuou "pari passu", desde o início do período de aplicação da nova lei, para prover apoio aos condomínios na necessária adequação às exigências regulamentares para a segregação dos resíduos, demonstrando assim a eficácia destas ações num importante parque de edificações urbanas positivamente impactadas por esta iniciativa.

\section{Origens e inspiração da iniciativa}

A inspiração para a realização do PCS encontrou suas origens nos 17 ODS da ONU, conforme já mencionado, e também nos processos das certificações ambientais aplicadas em grandes obras de edificação de caráter comercial, como a LEED do Green Building Council, AQUA (Alta Qualidade Ambiental) da Fundação Vanzolini e o selo Procel Edifica criado pela Eletrobras, dentre outra. A título de exemplo, a certificação LEED Platinum implica a promoção da Educação Ambiental entre os gestores, residentes e funcionários, destacando conceitos de uso racional do recurso hídrico, segregação adequada e redução dos resíduos gerados como item mandatório para a obtenção do selo de certificação.

Assim, o Programa Condomínio Sustentável buscou adequar para as edificações residenciais a proposta e a expertise das certificações ambientais tradicionais e, com o apoio da Prefeitura de Santos, realizou sua primeira fase, entre setembro de 2017 e agosto de 2018. Atualmente, desde dezembro de 2019 desenvolve sua segunda etapa, que deverá ser concluída até o início de 2021. Em ambas as edições, o programa recebeu fomento do Fundo Municipal de Preservação e Recuperação de Meio Ambiente (FMPRMA) do município de Santos, que identificou o potencial de abrangência e o valor da iniciativa. 
$\mathrm{Na}$ fase 1, o programa visitou mais de 1700 condomínios nos sete bairros da orla da cidade: José Menino, Pompéia, Gonzaga, Boqueirão, Embaré, Aparecida e Ponta da Praia, tendo realizado 122 atendimentos efetivos em condomínios participantes da ação, quatro eventos específicos para o setor condominial, com cunho informativo e ênfase nas soluções sustentáveis, contando com média de participação de 80 pessoas cada.

Agora, na segunda fase, o programa teve o escopo de atuação voltado para os demais bairros da cidade, situados nas Zonas Intermediária (Marapé, Campo Grande, Encruzilhada, Macuco, Estuário, Vila Belmiro, Jabaquara, Vila Mathias, Vila Nova) e Zona Noroeste (Saboó, Areia Branca, Castelo, Caneleira), além da atuação prevista em 13 unidades municipais de ensino (UMEs).

Visando promover a aplicação da nova lei, o programa desenvolve a prestação gratuita de consultoria em sustentabilidade para condomínios por meio de diagnósticos que identificam soluções nos três eixos de atuação: gestão de resíduos, eficiência energética e uso racional da água.

Para incentivar práticas sustentáveis e promover a formação de multiplicadores de seus conceitos, o PCS apoia-se nos pilares da Educação Ambiental como forma de estreitar a relação da sociedade com o meio ambiente e dar impulso à responsabilidade compartilhada, ampliando assim a rede de colaboradores do programa.

\section{Metodologia de trabalho}

A execução do Programa Condomínio Sustentável se inicia com a delimitação da área geográfica a ser atendida e a realização do inventário e identificação dos condomínios que possuem as características definidas no plano de atendimento, que nas duas fases priorizou edificações residenciais de médio e grande porte. Após estas definições, a região é mapeada para otimizar o processo de entrega dos ofícios dirigidos aos síndicos com o convite para os condomínios participarem do programa. A partir daí, os síndicos interessados entram em contato com a equipe do PCS a fim de agendar as visitas de diagnóstico.

Nestas visitas, os técnicos entregam o folder do projeto (Figura 1) e avaliam, por meio de um checklist, os parâmetros, estruturas e práticas adotadas pelos condomínios considerando os eixos da gestão de resíduos, uso racional da água e eficiência energética (Figura 2). A partir disso, é elaborado um pré-relatório, em versão Beta, que é apresentado posteriormente ao síndico para avaliação preliminar e possível inclusão de alguma outra informação que ele considere imprescindível. Esta versão inicial do relatório possibilita a participação do síndico na construção do conteúdo e na avaliação dos resultados, além de auxiliar no esclarecimento de dúvidas, compartilhamento de ideias e considerações sobre eventuais limitações ou dificuldades identificadas em relação às recomendações apresentadas. 


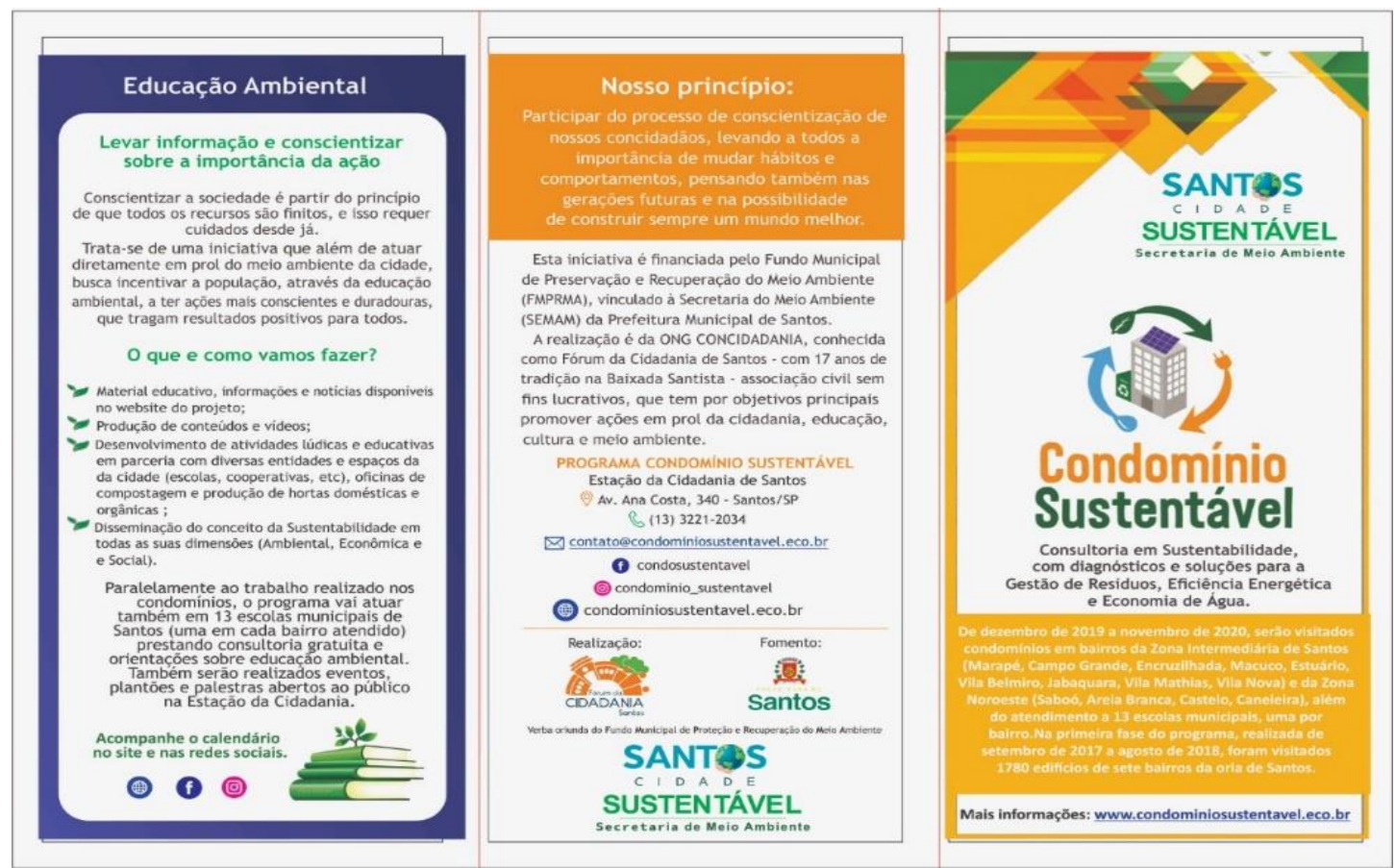

Figura 1: Folder de apresentação do projeto entregue aos moradores e síndicos. Fonte: Própria

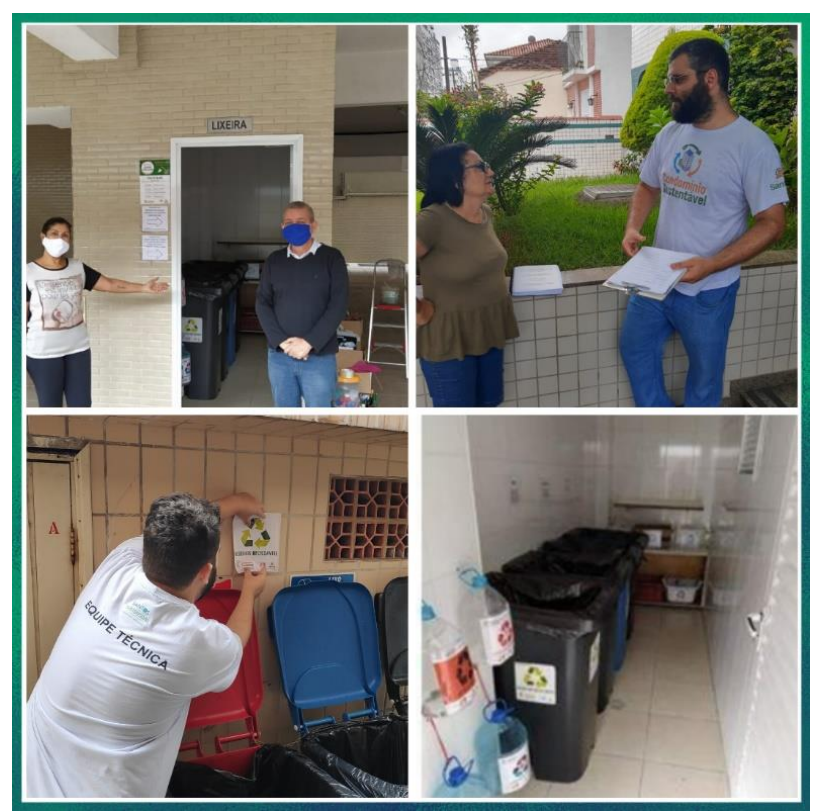

Figura 2: Ações desenvolvidas pelo programa, visitas técnicas, palestras, apresentações e disponibilização de kits informativos. Fonte: Própria

Uma vez incorporadas as observações e contribuições do síndico, é elaborada a versão final do relatório diagnóstico, que é entregue ao condomínio juntamente com o kit de comunicação visual e sinalização do programa, além do certificado de participação. Este kit consiste de cartazes informativos a serem afixados em elevadores e áreas comuns, adesivos de identificação 
relativos às diversas categorias de resíduos e folderes educativos para distribuição entre os moradores.

A equipe técnica do PCS acompanha todas as etapas do processo e colabora com a implementação das ações e adequação dos espaços destinados à gestão dos resíduos.

Neste aspecto, dentre as diversas questões avaliadas, são considerados os diferentes tipos de resíduos armazenados, o tamanho do espaço destinado a este fim, o revestimento, a exposição dos contentores, a acessibilidade e principalmente, as formas de sinalização dentro do condomínio. Além das questões relacionadas às exigências estabelecidas na lei municipal 952/2017, o programa também enfatiza a importância da segregação dos resíduos especiais, considerando, sobretudo, as variáveis da logística reversa e sua inerente importância como um passo além na gestão dos resíduos. Feito isso, o programa entende que os resíduos se destacam em uma nova categoria, deixando de ser assimilados ao conceito de "lixo" e passando a se tornar um produto valorizado e passível de monetização.

Para dar suporte às adequações implementadas, o programa oferece ainda o Manual do Condomínio Sustentável (Figura 3), disponível para download no site institucional e que agrega conteúdos de referência em mais de 50 páginas de informações de grande relevância para os síndicos e gestores.

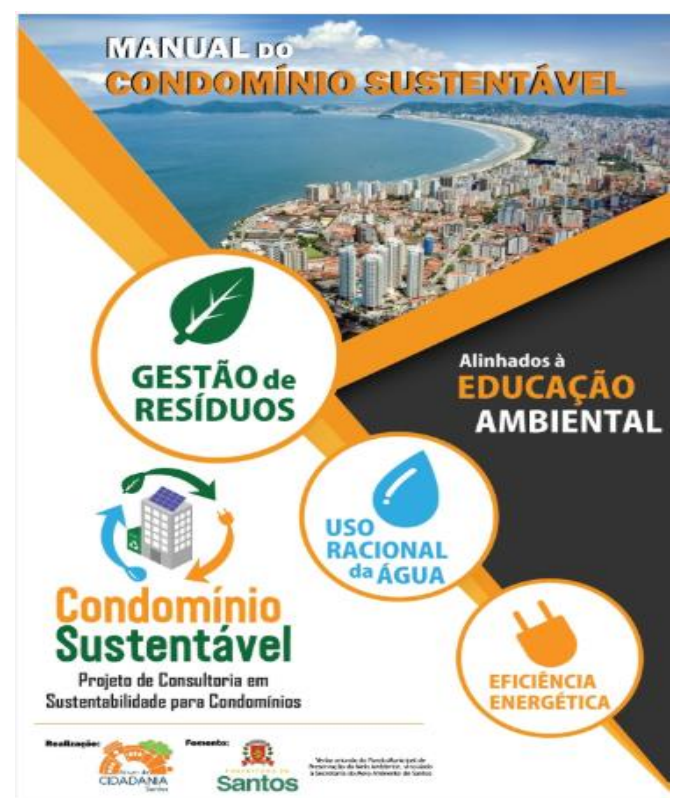

Figura 3: Manual do Condomínio Sustentável. Fonte: Própria.

Contudo, para garantir a eficácia da gestão dos resíduos, é fundamental a assimilação desses novos conceitos por toda a comunidade que integra o condomínio, de residentes e visitantes a colaboradores e prestadores de serviço. Por essas razões, o PCS coloca a Educação Ambiental como elemento fundamental deste processo ao lançar mão das mais variadas 
estratégias para comunicar seus conceitos, como a distribuição dos materiais informativos e a utilização de ferramentas digitais de comunicação, incluindo redes sociais e mídia interna com conteúdos específicos instalada nas dependências do condomínio.

Além destas ações estratégicas, o programa sugere ainda a realização de parcerias que podem contribuir, orientar e potencializar soluções para as principais demandas que surgem na busca pela excelência em sustentabilidade condominial. Algumas destas parcerias estão integradas à estrutura da própria ONG Concidadania, responsável pelo PCS. É o caso do Coletivo Composta \& Cultiva (C\&C), que provê soluções para a valorização dos resíduos orgânicos por meio da compostagem, dentro ou fora do condomínio, ou ainda internamente nos apartamentos, com o uso de minhocários ou de contentores especiais para coleta de resíduos orgânicos.

A segunda etapa do PCS também ampliou seu raio de atuação na direção das unidades municipais de ensino (UME), realizando diagnóstico técnico de sustentabilidade das edificações escolares, uma em cada bairro atendido, além de uma ação específica de Educação Ambiental junto aos alunos e professores buscando conscientizar a comunidade escolar com relação aos temas abordados e a responsabilidade de cada um diante do futuro do planeta.

O material desenvolvido para as atividades com os alunos considera as adaptações necessárias às diferentes faixas etárias em cada escola. Assim, o programa propõe uma série de ações com diferentes abordagens como oficinas, gincanas e games, atividades de reciclagem de brinquedos, plantio de horta comunitária e um quiz elaborado por educadores ambientais, que avalia o nível de conhecimento da comunidade escolar e incentiva o aprofundamento das informações relacionadas à sustentabilidade.

\section{A comunicação como ferramenta de base do programa}

Integrada à metodologia do PCS e como elemento fundamental para a disseminação das informações, a comunicação é utilizada como ferramenta basilar da Educação Ambiental. As estratégias mais abrangentes de comunicação envolvem sobretudo as plataformas digitais, com produção e divulgação de conteúdos e materiais destinados, não apenas aos condomínios participantes, mas também para a sociedade em geral.

O portal www.condominiosustentavel.eco.br foi idealizado como um website dinâmico e responsivo, e foi desenvolvido por meio de uma plataforma robusta, que integra um SGBD (Sistema de Gerenciamento de Banco de Dados) que possibilita administrar num único local os dados e informações armazenados, com tecnologia em nuvem, implicando assim os aspectos de segurança da informação, contingência e manutenção (Figura 4). Em termos de estrutura, o portal dispõe de várias rubricas de informação, atualidades, um blog com artigos técnicos renovados regularmente, dicas e informações de utilidade pública, conteúdos e documentos para download, ferramentas 
integradas com localizadores de pontos de reciclagem, dentre outras facilidades. Vale ressaltar ainda o "Quiz da Sustentabilidade", já citado anteriormente, que propõe um jogo interativo em diferentes níveis com conteúdo específicos sobre os quatro eixos do programa (resíduos, água, energia e Educação Ambiental). O game possibilita aprender brincando e serve de apoio para as ações realizadas em escolas e outros espaços de apresentação da iniciativa.

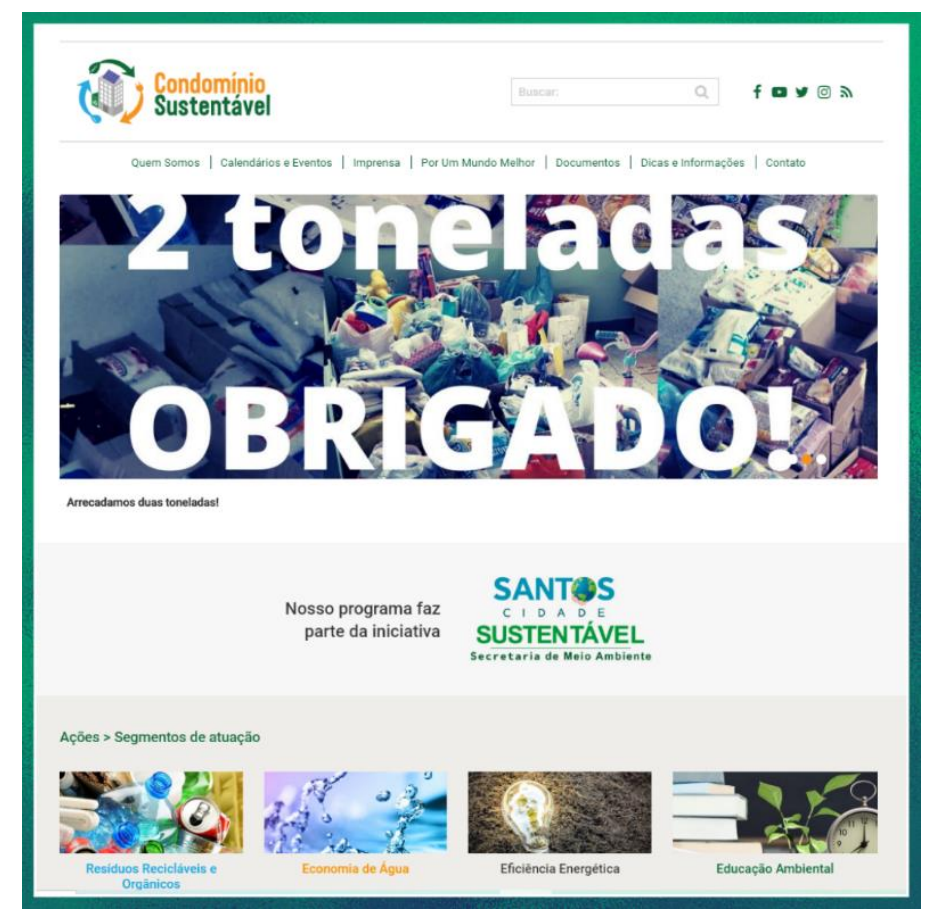

Figura 4: Website do programa. Fonte: Própria

O kit informativo (Figura 5) entregue aos condomínios é uma ferramenta primordial de incentivo às práticas de sustentabilidade. $O$ material visual é de fácil compreensão e contribui para prestar orientações e sanar eventuais dúvidas de moradores, funcionários e gestores. Desta forma, a comunicação visual do programa promove o envolvimento das pessoas nas diferentes ações realizadas nos condomínios, como a separação dos resíduos secos, úmidos e especiais, produção e cuidado de hortas comunitárias, construção de composteiras, instalação de redutores de vazão, instalação de sistema de captação da água de chuva e combate ao desperdício de recursos. Assim, as peças de comunicação visual e o incentivo à adoção de atitudes ecologicamente corretas auxiliam de forma significativa no desenvolvimento da Educação Ambiental e sua consequente eficiência no propósito de transformar a sociedade.

Além das ações promovidas dentro dos condomínios, o PCS também estabelece conexão com a sociedade em variados níveis de interação ao realizar eventos e palestras com convidados especialistas nos temas correlatos aos princípios do programa. 


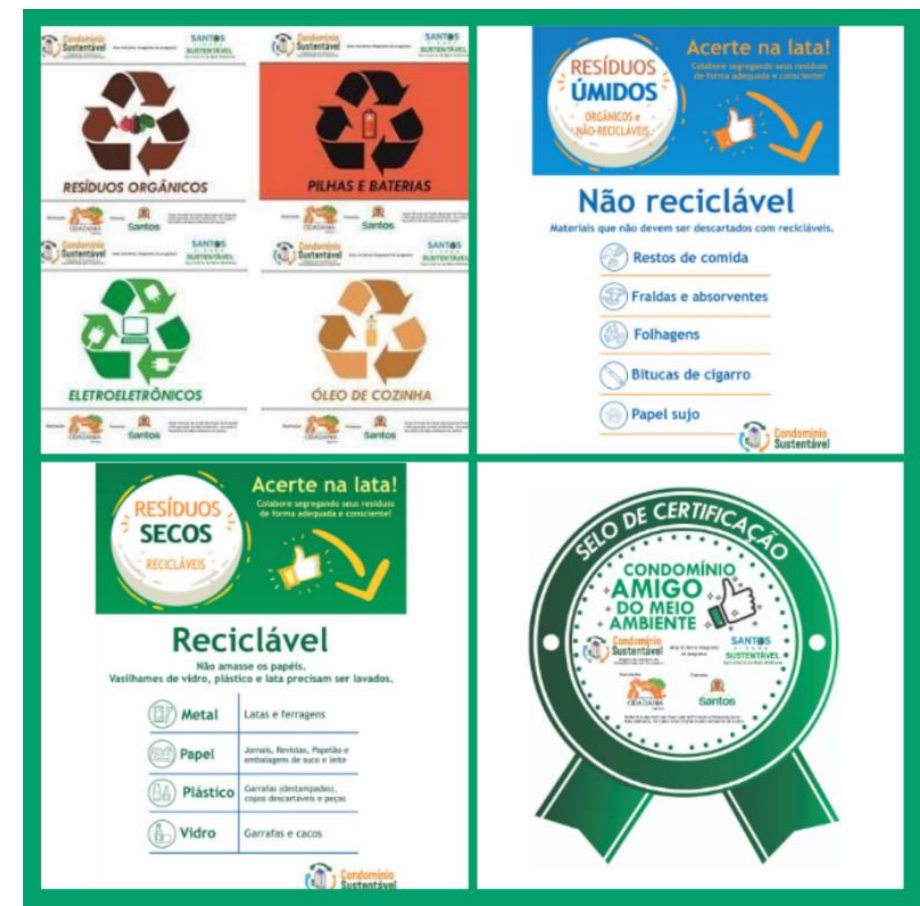

Figura 5: Sinalização, cartazes e selo de certificação para condomínios. Fonte: Própria

Na primeira fase, foram realizados quatro grandes eventos, com média de participação acima de 80 pessoas. O primeiro deles contou com a presença de Kevin Drew (Figura 6), professor em Berkeley, responsável pela gestão de resíduos domiciliares de San Francisco na Califórnia, que fez uma explanação sobre o conceito do Resíduo Zero na sede da Praticagem de Santos, contando com ampla cobertura da imprensa. Para os demais eventos, foram convidados especialistas em energias renováveis e gestão sustentável em condomínios.

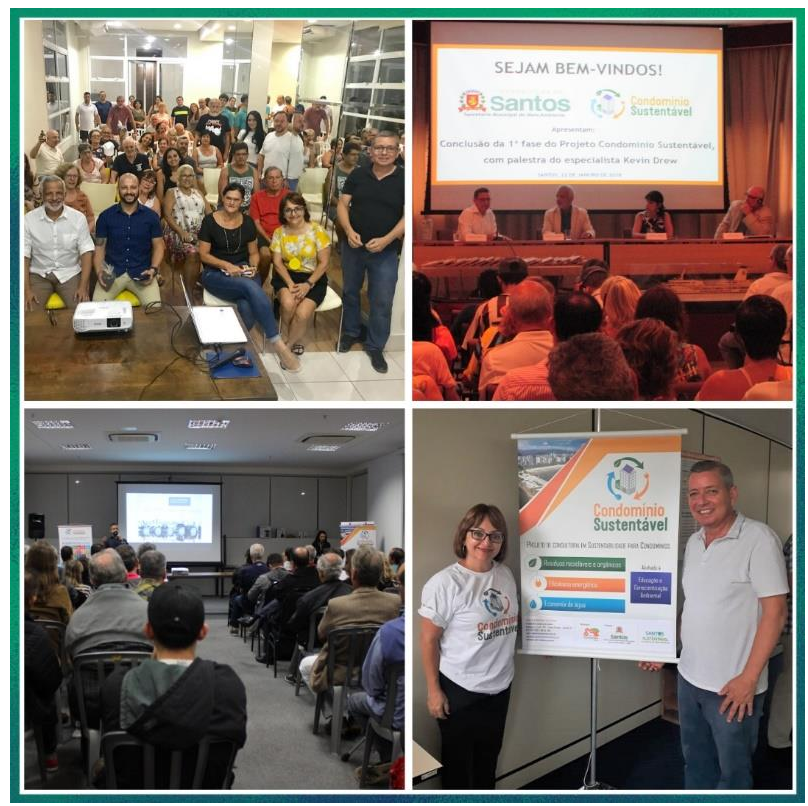

Figura 6: Palestras, apresentações e conversas com especialistas em sustentabilidade. Fonte: Própria.

Revbea, São Paulo, V. 15, № 5: 282-298, 2020. 
As redes sociais do Programa Condomínio Sustentável, como Facebook, Instagram e Youtube, são atualizadas regularmente com conteúdos diversos, incluindo-se vídeos educativos e informativos, campanhas específicas, além de datas comemorativas do calendário ambiental, sempre mantendo uma relação direta com as ações do programa e incentivando o exercício da cidadania (Figura 7).

Mais recentemente, o contexto do isolamento social provocado pela pandemia da covid-19 em 2020, com novas orientações para mitigar os riscos de contágio pelo coronavírus, fez as plataformas de comunicação do PCS serem utilizadas para divulgar informações de utilidade pública com a produção de conteúdo destacando as medidas aplicáveis aos condomínios, como a higienização das áreas comuns, aspectos inerentes aos cuidados com a gestão dos resíduos, proteção de funcionários e colaboradores, dentre outras (Figura 7).

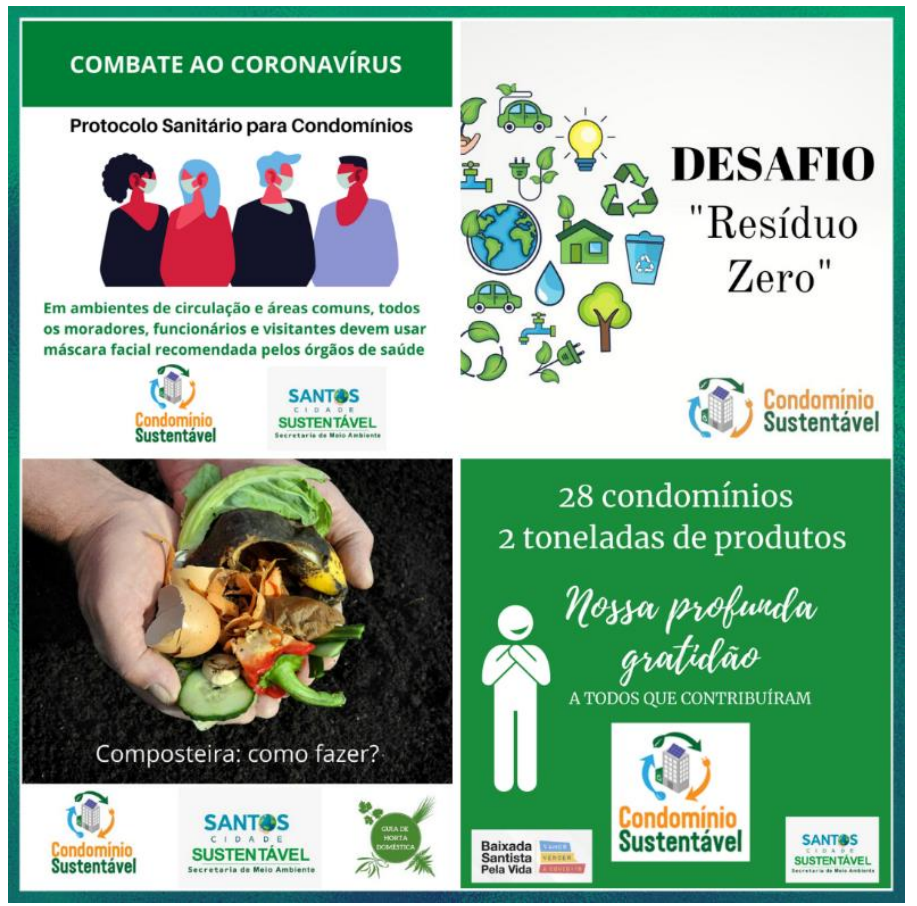

Figura 7: Posts das redes sociais, campanha de combate ao coronavírus, desafios, guia de horta doméstica, e arrecadação de doações durante a pandemia. Fonte: Própria.

Por fim, considerando os impactos econômicos da pandemia, o programa aderiu às campanhas solidárias da região e mobilizou uma rede de condomínios numa importante ação de doação de alimentos não perecíveis e produtos de higiene e limpeza para a população carente da Baixada Santista. Esta ação envolveu cerca de 30 condomínios e culminou com a arrecadação de mais de duas toneladas de produtos que beneficiaram aproximadamente 100 famílias em situação de vulnerabilidade na região (Figura 7). Este esforço se insere diretamente nas metas específicas dos ODS 1, 2 e 3, que destacam respectivamente a erradicação da pobreza e da fome, além da saúde e bem 
estar; corroborando assim com os princípios que orientaram a criação do PCS e que caracterizam a sustentabilidade como um conceito mais amplo e abrangente.

\section{Construindo o futuro que queremos}

No âmbito da sustentabilidade, o período de pandemia permitiu evoluir numa ampla reflexão sobre a forma como a sociedade moderna extrai, utiliza e descarta os recursos do planeta. Para além das questões de produção, consumo e descarte, a reflexão englobou também a forma como trabalhamos, nos deslocamos, comunicamos e em todas elas foi possível identificar alternativas que possibilitam racionalizar os processos e com isso reduzir nossa pegada ecológica. $O$ isolamento social nos fez perceber, assim como também remarcou o filósofo francês Bruno Latour que "era possível parar", reduzindo o ritmo frenético da sociedade moderna e consequentemente reduzindo também as emissões de gases de efeito estufa.

Esta maior consciência situacional em nossas rotinas domiciliares também se alterou. Tanto os moradores, quanto o poder público tiveram que se adequar a essa nova realidade. Umas das principais adequações foi com relação ao manejo de resíduo sólido domiciliar, com aumento na produção de recicláveis secos, como plásticos, vidro, papel e metal, devido a maior demanda dos serviços de delivery, ou entrega em domicílio, despertando assim a atenção da sociedade para a questão da destinação e quantidade de resíduos domésticos gerados.

Durante este período, os serviços de coleta de resíduos e limpeza urbana, e a ação das cooperativas de catadores de materiais recicláveis foram reconhecidos como essenciais para as cidades, embora ainda careçam de valorização profissional das categorias e de melhores condições de trabalho.

O aumento da geração de resíduos domésticos e a importância destes trabalhadores são apenas dois exemplos de aspectos que precisam receber maior atenção da sociedade neste momento de grandes mudanças rumo ao "novo normal", que virá pós pandemia.

Para tentar ajustar esse foco, basta lembrar que atualmente, a média nacional do índice de reciclagem de resíduos é de apenas 3\% (ABRELPE, 2019) e isto remete a um desperdício enorme de matéria-prima e energia, o que potencializa ainda mais os danos ambientais no planeta.

Neste sentido, as propostas do Programa Condomínio Sustentável e ações similares de outros programas que desenvolvem a Educação Ambiental podem e devem ser utilizadas como ferramentas integradoras e incentivadoras para a conscientização da sociedade e para a gestão adequada dos resíduos sólidos envolvendo poder público, iniciativa privada, organizações da sociedade civil e o próprio cidadão individualmente.

A metodologia e os conceitos do PCS como ferramentas de adequação dos condomínios residenciais às demandas ambientais do período pós 
pandemia podem contribuir para uma robusta ação de Educação Ambiental facilmente aplicável e replicável em qualquer município.

Há, portanto, diversas alternativas de viabilidade financeira para a implantação do programa em qualquer tipo de condomínio e nas mais diversas especificidades regionais. Essa possibilidade de "customização" é o que torna o PCS facilmente exequível e inspirador.

O êxito das ações de Educação Ambiental empreendidas diretamente, ou através de parcerias e editais, que contribuíram para a otimização dos processos de gestão demonstram o caminho que possibilita avançar na implementação completa do PNRS. Neste sentido, o programa demonstrou eficiência e comprometimento com a promoção de práticas sustentáveis nos condomínios residenciais, estendendo-se até o ambiente escolar, com grande potencial multiplicador.

Por último, repensar os hábitos individuais com vistas ao consumo consciente e o combate ao desperdício e ao consumismo desenfreado devem fazer parte da agenda a ser observada agora, durante a pandemia e, sobretudo, no período vindouro, já denominado como "novo normal". Esta é a urgência da sociedade pois, em se mantendo a atual pressão sobre os recursos naturais, o avanço do desmatamento e da poluição que reforçam o fenômeno das mudanças climáticas, o planeta poderá entrar em colapso ambiental com escassez de recursos, extinção de espécies e comprometimento brutal da qualidade de vida e até da sobrevivência da espécie humana.

O importante legado desta pandemia é justamente a oportunidade de reflexão sobre o modo de vida contemporâneo, considerando a preservação da saúde, as novas formas de trabalho, o inédito perfil da economia, os deslocamentos urbanos, os inovadores métodos de ensino e aprendizagem, as crescentes possibilidades tecnológicas de comunicação e, sobretudo, as reais necessidades da sociedade em relação ao que consome e como lida com os resíduos gerados por suas atividades.

\section{Conclusões}

As ações do PCS permitem contribuir para uma significativa elevação dos índices de reciclagem nos municípios densamente verticalizados, mas podem também ser replicadas em ambientes e edificações com características diferentes. O processo de promoção de práticas mais sustentáveis do manejo dos resíduos sólidos através da Educação Ambiental tem o potencial de transformar moradores, colaboradores e síndicos em multiplicadores dos conceitos da sustentabilidade.

A necessidade de organizar e responsabilizar a sociedade sobre a gestão de resíduos sólidos é urgente diante do atual cenário de crise climática e degradação do meio ambiente. Durante o período da pandemia da covid-19, essa necessidade ficou ainda mais evidente e alguns hábitos precisam ser 
ressignificados para garantir nosso futuro comum. Portanto, da realidade que enfrenta hoje em dia, a sociedade não pode retroceder para o "antigo normal".

Um futuro mais sustentável precisa ser visto não como uma alegoria de um grupo de pessoas ligadas às questões ambientais, mas sim como uma estratégia de sobrevivência para a humanidade e demais espécies do planeta. Somente através de uma efetiva educação e conscientização ambiental em todos os níveis, com base interdisciplinar e cívica, será possível avançar com responsabilidade para o "novo normal" que se anuncia e o Programa Condomínio Sustentável destaca e responsabiliza o papel do cidadão como elemento fundamental neste processo.

\section{Agradecimentos}

O sucesso desse programa só tem sido possível graças ao precioso apoio dos parceiros e instituições, dentre elas a ONG Consciência Pela Cidadania CONCIDADANIA (entidade organizadora), incluindo o conjunto de sua equipe de coordenação, associados e voluntários; o Sindicato de Condomínios Prediais do Litoral Paulista (SICON); síndicos e administradoras prediais que receberam e divulgaram nossas ações. Além do agradecimento especial à Prefeitura Municipal de Santos, através da Secretaria de Meio Ambiente (SEMAM) e de suas equipes, e por extensão também ao Fundo Municipal de Preservação e Recuperação do Meio Ambiente (FMPRMA) que proveu os recursos para o fomento e a realização deste programa em suas duas fases até aqui.

\section{Referências}

ALVES, H. P. F. Desigualdade ambiental no município de São Paulo: análise da exposição diferenciada de grupos sociais a situações de risco ambiental através do uso de metodologias de geoprocessamento. Revista Brasileira de Estudos de População, [s.l.], v. 24, n. 2, p. 301-316, dez. 2007.

ASSOCIAÇÃO BRASILEIRA DE DE EMPRESAS DE LIMPEZA PÚBLICA E RESÍDUOS ESPECIAIS (ABRELPE). Panorama dos resíduos sólidos no Brasil 2018/2019. São Paulo: ABRELPE, 2019.

BRAGA JUNIOR, S. S.; PINHEIRO, L. R. D. A importância da reciclagem dos resíduos sólidos dentro das organizações. Revista Brasileira de Engenharia de Biossistemas, v. 7, n. 1, p. 55-69, nov. 2013.

BRASIL. Lei no 12.305, de 2 de agosto de 2010. Institui a política nacional de resíduos sólidos. Brasília, DF: Diário Oficial da União, 2010.

FREIRE, P. Pedagogia do oprimido. 8를 ed. Rio de Janeiro: Paz e Terra, 1980. JACOBI, P. R.; BESEN, G. R. Gestão de resíduos sólidos em São Paulo: desafios da sustentabilidade. Estudos Avançados, São Paulo, v. 25, n. 71, p. 135-158, abr. 2011. 
NOUAILLAS, O. Bruno Latour, Nicolas Hulot, François Ruffin: comment le covid-19 peut relancer la mutation écologique. Lavie, Paris, abr. 2020. Disponível em: <http://www.lavie.fr/actualite/ecologie/bruno-latour-nicolas-hulotfrancois-ruffin-comment-le-covid-19-peut-relancer-la-mutation-ecologique-1404-2020-105490 8.php> Acesso em: 06/06/2020

ORGANIZAÇÃO DAS NAÇÕES UNIDAS (ONU). Transforming our world: The 2030 Agenda for sustainable development. Nova lorque, 2015.

PREFEITURA MUNICIPAL DE SANTOS. Coleta de materiais recicláveis aumenta em $300 \%$ 2019. Disponível em: $<$ https://www.santos.sp.gov.br/?q=noticia/coleta-de-materiais-reciclaveisaumenta-300>. Acesso em: 20/05/2020.

QUINTAS, J. S. A educação no processo de gestão ambiental. In: BRASIL, MINISTÉRIO DA EDUCAÇÃO. Salto para o Futuro: Educação Ambiental no Brasil. Brasília, 2008. p. 30-41.

SILVA, S. P. A organização coletiva de catadores de material reciclável no Brasil: dilemas e potencialidades pela ótica da economia solidária. Rio de Janeiro: Livraria IPEA, 2017. 48 p.

SOUSA, D. C. G. et al. A importância da reciclagem do papel na melhoria da qualidade do meio ambiente. Anais do XXXVI Encontro Nacional de Engenharia de Produção. Contribuições da Engenharia de Produção para Melhores Práticas de Gestão e Modernização do Brasil. Rio de Janeiro: Abepro, $2016 . \quad$ p. $\quad 1-16$. Disponível $<$ http://www.abepro.org.br/biblioteca/tn sto 234366 30516.pdf> Acesso em: $03 / 05 / 2020$

VELLOSO, M. P. Os restos na história: percepções sobre resíduos. Ciência \& Saúde Coletiva, Rio de Janeiro, v. 6, n. 13, p. 1953-1964, fev. 2007. 